\title{
New excavations at Tappeh Asiab, Kermanshah Province, Iran
}

\author{
Hojjat Darabi ${ }^{1}$, Tobias Richter ${ }^{2, *} \&$ Peder Mortensen ${ }^{2}$
}

The site of Tappeh Asiab in Iran is one of only a handful of Early Neolithic sites known from the Zagros Mountains. Discovered during Robert Braidwood's 'Iranian Prehistory' project, the site has seen limited publication of its early excavations. Here, the authors challenge some of the initial assumptions made about the site by discussing the first findings of renewed excavations, in the hope of substantially improving our currently limited knowledge of the Early Neolithic in this region.

Tappeh Asiab is an Early Neolithic site situated on the outskirts of Kermanshah, in the central Zagros Mountains, of Iran (Figure 1). The site was found during Robert Braidwood's 'Iranian Prehistory' Project, and was briefly excavated early in 1960 under the direction of Bruce Howe (Braidwood \& Howe 1960; Braidwood et al. 1961; Howe 1983). Asiab was one of the first Early Neolithic sites excavated in the central Zagros, and although the excavations at the site were never comprehensively published, it has played an important role in shaping our understanding of the Early Neolithic in this region (Nashli \& Matthews 2013; Darabi 2015).

Howe described the deposits at Asiab as "a chaotic jumble of animal bones, freshwater clam shells, coprolites, flintworking and other artefactual debris, rocks and traces of fire and ash, as well as numerous debris-filled pits", covering an area of $20000 \mathrm{~m}^{2}$, of which $130 \mathrm{~m}^{2}$ was excavated (Howe 1983: 115). At the bottom of the main excavation area, Howe discovered "the vestige of a large shallow-basined oval excavation into virgin soil that suggested a refuse pit or possibly man-made semi-subterranean structure" (Howe 1983: 115; Figure 2). Two burials were found just above this structure in the debris (Howe 1983: 115). Based on the techno-typology of the chipped stone artefacts and radiocarbon dates, Howe placed the occupation at Asiab at around 8000 BC or later (Howe 1983: 115). Sadly, Howe's brief 1983 article, which lacks a site plan or accompanying photographs, is the most detailed description of his excavations, leaving questions concerning the chronology, site function and economy of the site unanswered.

The lack of published information about Asiab, as well as the considerable methodological advances in archaeological fieldwork methods made in the last 50 years, led us to initiate new excavations at Asiab in 2016, as part of the 'Tracking Cultural and Environmental Change: the Late Epipalaeolithic and Early Neolithic in the Seimarreh River

1 Department of Archaeology, Razi University, University Avenue, Taq-e Bostan, Kermanshah, Islamic Republic of Iran

2 Center for the Study of Early Agricultural Societies, University of Copenhagen, Building 10, Karen Blixens Plads 8, 2300 Copenhagen-S, Denmark

* Author for correspondence (Email: richter@hum.ku.dk)

(C) Antiquity Publications Ltd, 2018

ANTIQUITY 92 361, e2 (2018): 1-6

https://doi.org/10.15184/aqy.2018.3 


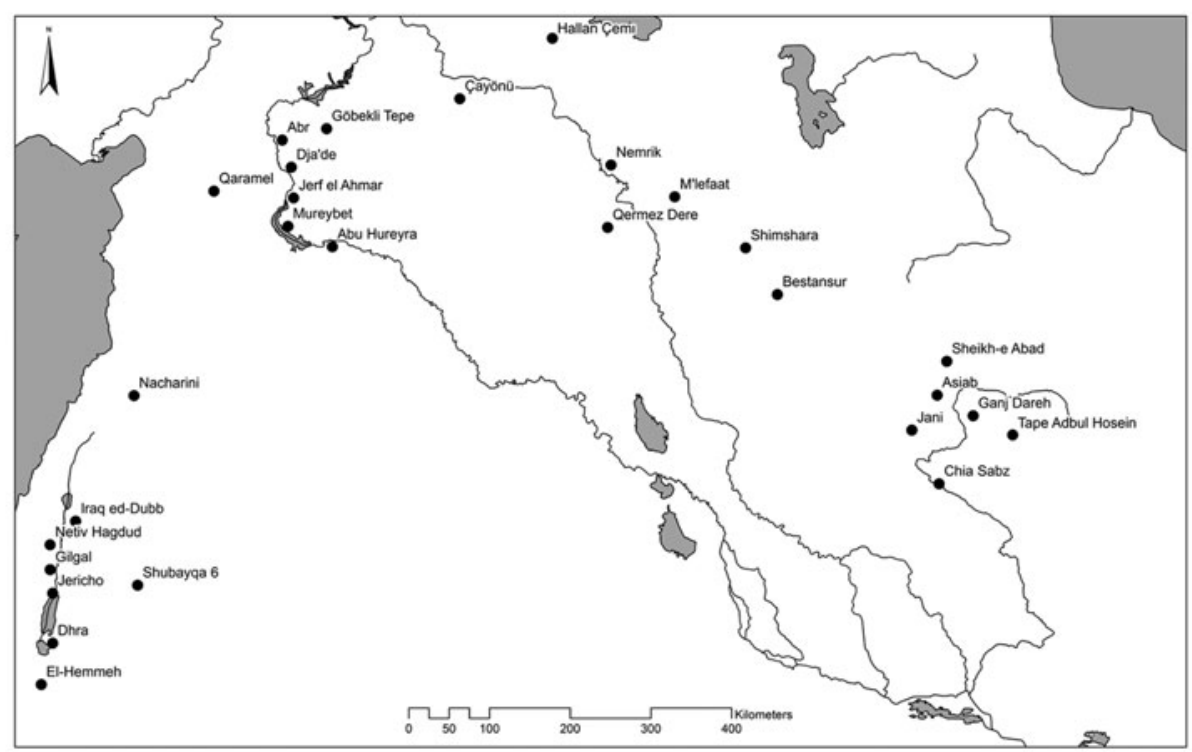

Figure 1. Location of key Early Neolithic sites in south-west Asia, including Asiab.

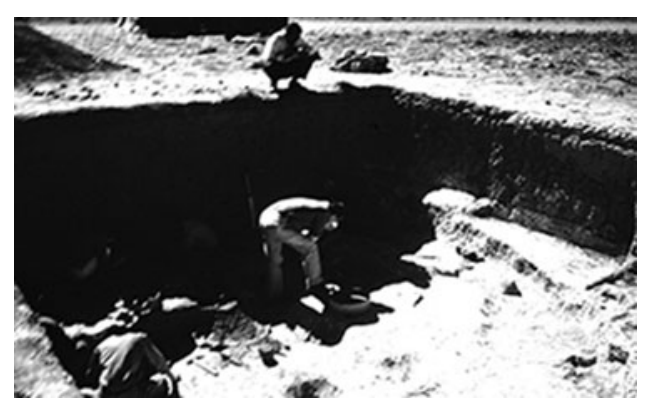

Figure 2. Photograph of Bruce Howe's main excavation area in early 1960, showing part of the large shallowbasined oval excavation into virgin soil (courtesy of Frank Hole)
Valley' (TCEC) project (www.tcec.ku.dk). Our excavations aimed to relocate and record Howe's main excavation area in order to determine the character of the shallowbasined oval feature that he reported, to record a detailed stratigraphic sequence for the site and to obtain samples of sediment and other finds from stratified deposits to facilitate the reconstruction of the environment, economy and chronology of Asiab.

Asiab is situated on a Pleistocene alluvial terrace of the Kara Su River, to the east of Kermanshah and south of the modern

village of Bijaneh (Figure 3). A lithic scatter extends approximately 0.36 ha across the top of the terrace. Our first step was to locate Howe's 1960 excavation area, and in particular, the large, deep trench visible in site photographs, which measured approximately $6 \times 8 \mathrm{~m}$ with a depth of approximately $2.5-3 \mathrm{~m}$. In 2016 we therefore opened three new excavation areas at Asiab (areas I-III). After removing the topsoil across a considerable area, Howe's old main excavation area was located in area III (Figure 4). Our excavations then focused on re-excavating Howe's main trench, as well as excavating a new $5 \times 5 \mathrm{~m}$ area adjacent to it in order to obtain stratified samples of finds and deposits.

(C) Antiquity Publications Ltd, 2018 
New excavations at Tappeh Asiab, Kermanshah Province, Iran

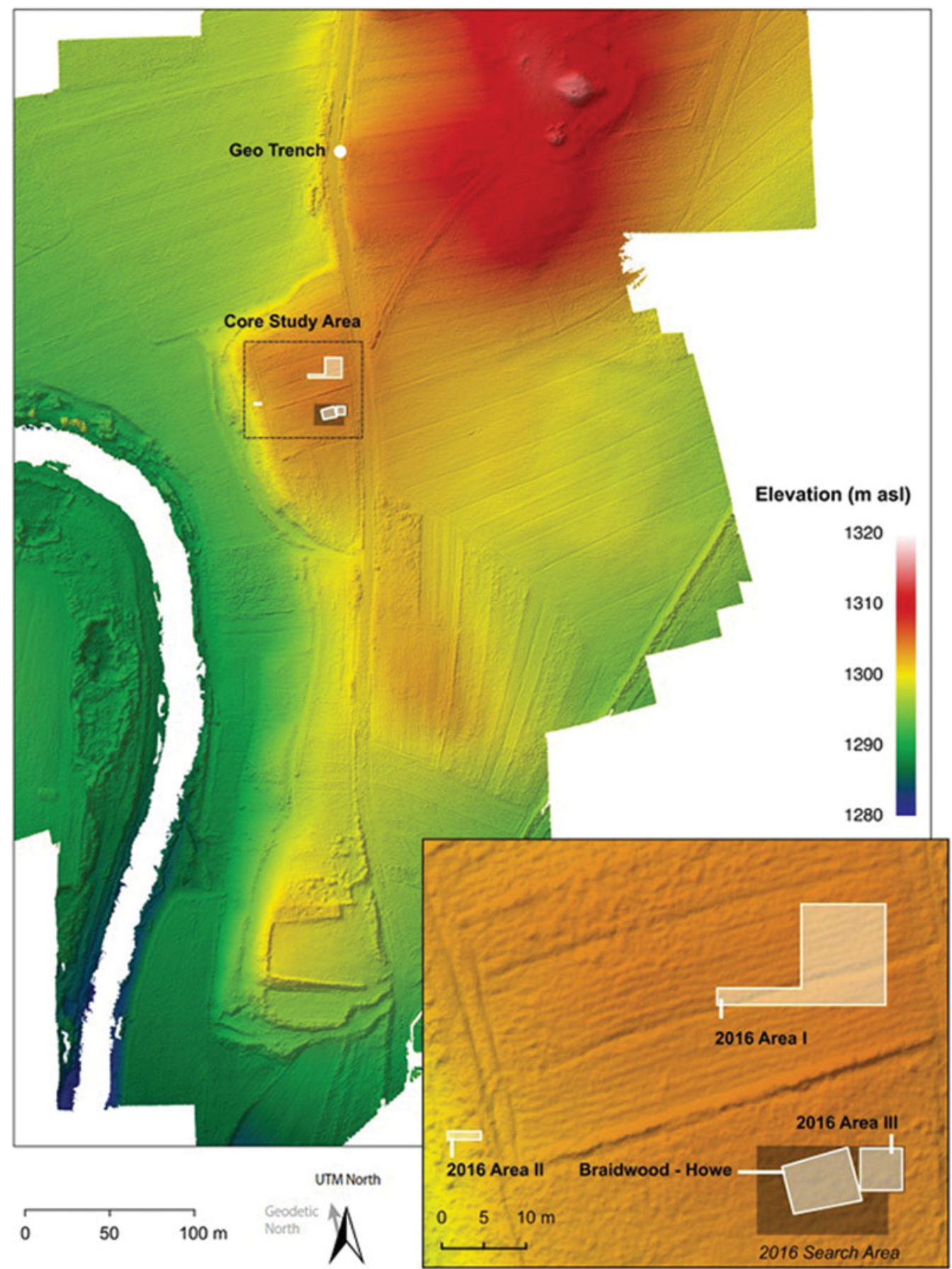

Figure 3. Digital elevation model of the Asiab terrace showing the 2016 excavation areas.

(C) Antiquity Publications Ltd, 2018 


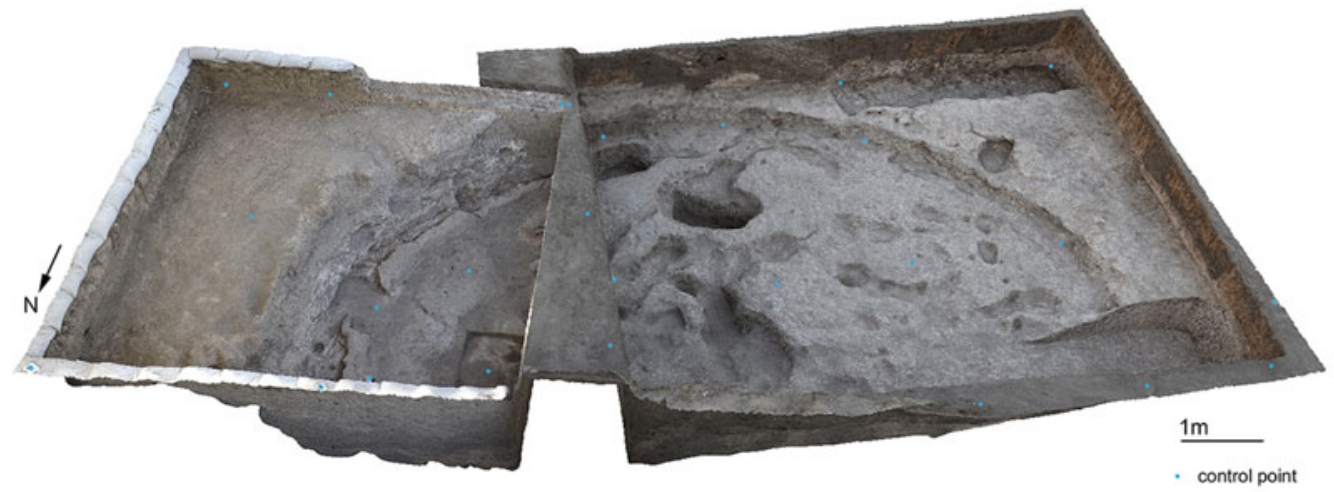

Figure 4. 3D photogrammetry of the 2016 Asiab excavations showing Bruce Howe's 1960 area on the right, as well as the new TCEC excavation area on the left.

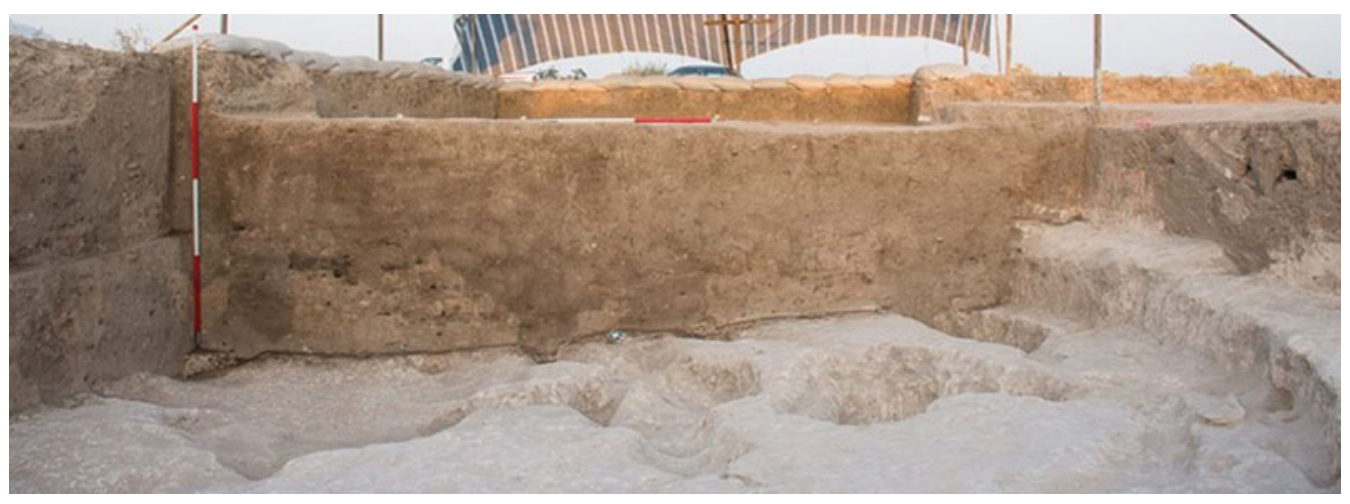

Figure 5. Animal burrows visible in the east section of Howe's excavation area (photograph by the excavation team; copyright University of Copenhagen and Razi University).

The re-excavation of Howe's area exposed two rectangular cuts measuring $2 \times 1 \mathrm{~m}$ in the north-west and south-west corners. These appear to be sondages dug by Howe to determine the presence of anthropogenic deposits. The sondage in the north-west corner truncated archaeological deposits, and hence Howe appears to have expanded his main trench out from these two sondages. Removal of the backfill revealed the shallow-basined oval feature described by Howe (Figure 4). Inside this feature we found several post- and stake-holes. Their precise stratigraphic relationship with the circular cut is unknown, as Howe excavated almost the entire area down to the underlying natural sediment. A long, shallow, ovalprofiled pit, apparently unnoticed or left unexcavated by Howe, was found to contain a cache of wild boar crania, which were tightly packed and neatly arranged in an east-west alignment.

The stratigraphic sections in Howe's old excavation confirmed his observation of two main layers, the upper of which was grey, while the lower one was tan in colour (Howe 1983: 115). Inspection also revealed disturbance related to vertical funnels, resulting from collapsed entryways to animal burrows visible at the base of the sequence (Figure 5). While (C) Antiquity Publications Ltd, 2018 


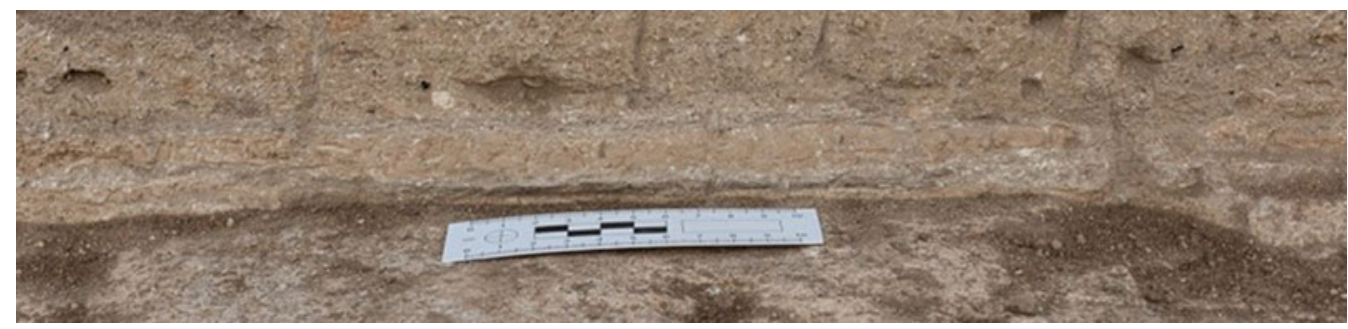

Figure 6. Close-up view of the two successive floors in the east section of Howe's excavation area. These floors would have covered the interior of Howe's oval feature, indicating that this was in fact a building (photograph by the excavation team; copyright University of Copenhagen and Razi University).

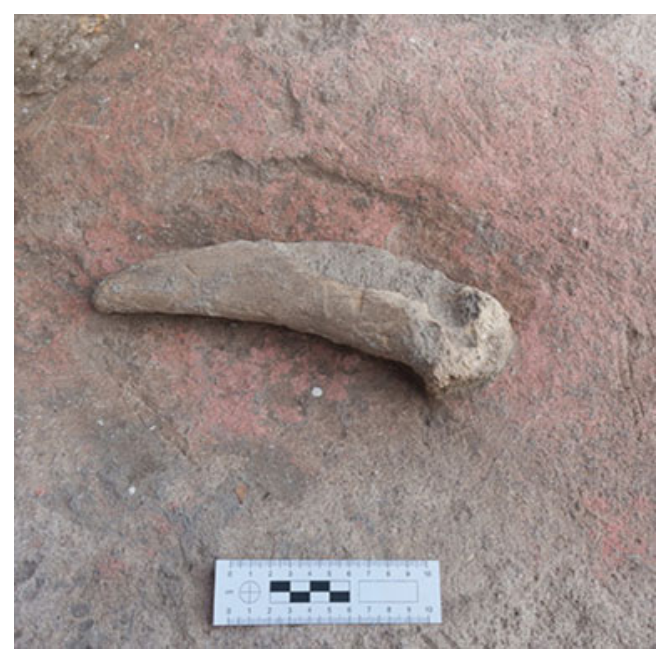

Figure 7. Cattle horn core placed in a shallow, ochrepainted depression on the floor of the large circular building at Asiab (photograph by the excavation team; copyright University of Copenhagen and Razi University). some in situ deposits remained, most of the stratigraphic sequence at Asiab was heavily disturbed by animals. Nevertheless, we were able to record two floor layers immediately above the natural clay, visible in the northern and eastern baulks of Howe's area (Figure 6). The circular cut was then filled in by an approximately 1.5 m-thick midden.

In the new $5 \times 5 \mathrm{~m}$ area adjacent to Howe's trench, we exposed the continuation of the circular feature exposed at the bottom of the 1960 excavation area. The feature was filled by midden deposits to a depth of $1.6 \mathrm{~m}$ and was cut into the subsoil immediately below the ploughzone. In Howe's trench, this cut appeared to be truncated upwards from a depth of $0.35 \mathrm{~m}$, which suggests that Howe removed most of the upper part of the feature during his excavation. Inside the feature we exposed a trampled floor layer. Along the edge of the cut, the remnants of a pisé wall became visible. This mud wall probably stood much higher originally. One area of the floor was shaped into a shallow depression and painted with red pigment. A cattle horn core was placed in the depression (Figure 7). Two caches of antlers were found: one inside the pisé wall, and the second lying on another part of the floor in the northern part of the trench.

Analysis of the recovered finds and samples is ongoing, but we are already able to draw some preliminary conclusions. The "refuse pit or possibly man-made semi-subterranean structure" that Howe (1983: 115) exposed was indeed a building with a probable exterior pisé wall, post-holes and well-defined floors. Much of this structure apparently went unrecognised by Howe. His excavation truncated the construction cut and the pisé wall, and it completely removed the floor. The anthropogenic sediments at Asiab are extremely

(C) Antiquity Publications Ltd, 2018 
disturbed by animal burrows, and their full extent was not recognised during the original excavations. In light of this, much of the previous data obtained from Asiab must therefore be considered problematic in terms of provenance. The deep construction cut, the remains of the building set within it and the midden filling of the pit appear to be the only remnants of Neolithic settlement at Asiab. While the remaining building was subterranean, the majority of the Neolithic settlement was located on the Neolithic land surface, which has since eroded away. Although a surface scatter of lithic artefacts extends around 0.38ha across the terrace, this is displaced residual material that does not reflect the original size of the settlement. In any case, there is no evidence to suggest that the site originally measured 2 ha in size as Howe originally suggested (Howe 1983). Revisiting Asiab has shed important new light on one of the few known Early Neolithic sites in the central Zagros. Our work has already suggested that the site is quite different to its original characterisation. Future analyses of the finds and samples from the excavations will further illuminate the true nature of this Early Neolithic settlement.

\section{Acknowledgements}

Excavations at Asiab were carried out by the TCEC project. TCEC is a collaboration between the Research Institute for Cultural Heritage, the Iranian Centre of Archaeological Research, the Department of Archaeology at Razi University and the Center for the Study of Early Agricultural Societies at the University of Copenhagen. The project is generously funded by a grant from the C.L. David Collection and Foundation. We are grateful to the representatives of the Kermanshah office of the Cultural Heritage, Handicrafts and Tourism Organisation for their support and assistance during the fieldwork, as well as to all the members of the Asiab fieldwork team.

\section{References}

Braidwood, R.J. \& B. Howe. 1960. Prehistoric investigations in Iraqi Kurdistan. Chicago (IL): University of Chicago Press.

Braidwood, R.J., B. Howe \& C.A. Reed. 1961. The Iranian prehistoric project: new problems arise as more is learned of the first attempts at food production and settled village life. Science 133: 2008-2010. https://doi.org/10.1126/science.133.3469.2008

Darabi, H. 2015. An introduction to the Neolithic revolution of the central Zagros, Iran. Oxford: Archaeopress.
Howe, B. 1983. Karim Shahir, in L.S. Braidwood, R.J. Braidwood, B. Howe, C.A. Reed \& P.J. Watson (ed.) Prehistoric archaeology along the Zagros flanks: 23-154. Chicago (IL): The Oriental Institute of the University of Chicago.

Nashli, H.F. \& R. MatThews. 2013. The Neolithisation of Iran: patterns of change and continuity, in R. Matthews \& H.F. Nashli (ed.) The Neolithisation of Iran: 1-13. Oxford: Oxbow. 